\title{
Dental Education and Changing Oral Health Care Needs: Disparities and Demands
}

\author{
Judith E.N. Albino, Ph.D.; Marita R. Inglehart, Dr. phil. habil.; Lisa A. Tedesco, Ph.D. \\ Abstract: The population of the United States has changed dramatically over recent decades and, with it, the oral health care needs \\ of the nation. Most notably, the racial/ethnic composition of the population has shifted from a European American majority to \\ what is now a much more diverse population, comprising a variety of racial/ethnic groups that, taken together, will become the \\ majority by mid-century. The proportion of children from minority racial groups will represent more than half of all U.S. children \\ by 2025 . These groups are overrepresented among those living below the poverty level and have higher levels of oral disease and \\ are less likely to have access to care than the European American segment of the U.S. population. Most of the population need- \\ ing dental care in the future will be comprised of these now underserved groups, along with other groups who can be described \\ in terms of the health and social challenges of aging, disabilities, or other special health care conditions. This article provides an \\ overview of these various needs and what they will mean for the dental practitioners of tomorrow and suggests that dental educa- \\ tion has not adapted to the changing population and its oral health needs as quickly as it should. As a result, we identify major gaps \\ in current dental curricula and make some recommendations for change. Research has shown that dental education has a crucial \\ influence on future providers' professional attitudes and behavior related to providing care for patients from underserved patient \\ groups. Acknowledging the specific needs of patients and ensuring that future providers are optimally prepared to respond to these \\ challenges must be a major goal of dental education in the twenty-first century. The Journal of Dental Education will continue to \\ play a critical role in informing readers about innovative approaches and best practices that ensure this goal can be met.
}

Dr. Albino is Principal Investigator and Director of the Center for Native Oral Health Research, University of Colorado Denver; Dr. Inglehart is Associate Professor, Department of Periodontics and Oral Medicine, School of Dentistry, University of Michigan; and Dr. Tedesco is Vice Provost for Academic Affairs-Graduate Studies and Dean of the James T. Laney School of Graduate Studies, Emory University. Direct correspondence and requests for reprints to Dr. Marita R. Inglehart, Department of Periodontics and Oral Medicine, School of Dentistry, University of Michigan, 1011 North University Avenue, Ann Arbor, MI 48109-1078; 734-763-8073 phone; 734-763-5503 fax; mri@umich.edu.

Keywords: dental education, demographic change, patients with special needs, access to oral health care, oral health of children, underrepresented minorities, children, socioeconomically disadvantaged, poverty

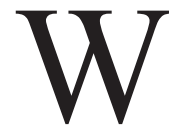
hen the first issue of the Journal of Dental Education (JDE) was published in 1936, the U.S. population stood at $128,053,180 .{ }^{1}$ By mid-2011, that number had grown almost threefold, to exceed $311,800,000 .^{2}$ This tremendous increase was accompanied by equally significant changes in the racial/ethnic composition and age distribution of the population as well as in greater numbers of individuals living with physically, mentally, and/or socially compromised conditions. These changes can be expected to continue over the next decades (Table 1). In 1936, for example, the percentage of individuals of Hispanic origin living in the United States was not even reported, whereas by 2050 , it is predicted that more than two out of ten will be Hispanic and a majority of the population will be of racial/ethnic groups other than European American. In fact, the number of children who are Hispanic already surpasses the 50 percent mark in many of our largest cities. Moreover, the percentage of the U.S. population over the age of sixty-five had reached 13 percent in the 2000 census and can be expected to approach 20 percent by 2030; those eighty years of age and over (more than 3 percent) now constitute one of the fastest-growing segments of the population. ${ }^{3}$ In fact, addressing the needs of all of these growing sectors of the population - with their higher levels and sometimes different manifestations of oral disease and their inadequate access to appropriate prevention and treatment opportunities - should be considered one of the most important new missions of the dental profession.

While the legal landscape of the United States in 1936 was quite different from that of today, the changes that have occurred over the decades have not erased disparities in oral health and access to treatment. In 2000, the first report of the surgeon general on oral health ${ }^{4}$ focused attention on segments of the population that disproportionately experience oral disease; the report also highlighted the challenges experienced by those underserved populations in accessing oral health care services, with respect to both treatment and prevention. The report concluded that not all population segments have the same opportunities for good oral health and access to oral health care services. Individuals from socioeconomically 
Table 1. Changing percentage of racial/ethnic groups in the total U.S. population

\begin{tabular}{|c|c|c|c|c|}
\hline Race/Ethnicity & 1950 & 2000 & 2010 & 2050 \\
\hline White & $89.5 \%$ & $75.1 \%$ & $72.4 \%$ & $74.0 \%$ \\
\hline Non-Hispanic white & & $69.1 \%$ & $63.7 \%$ & $52.5 \%$ \\
\hline Hispanic/Latino & & $12.5 \%$ & $16.3 \%$ & $22.5 \%$ \\
\hline Black or African American & $10.0 \%$ & $12.3 \%$ & $12.6 \%$ & $15.7 \%$ \\
\hline Asian American & $0.2 \%$ & $3.6 \%$ & $4.8 \%$ & $10.3 \%$ \\
\hline American Indian and Alaska Native & $0.2 \%$ & $0.9 \%$ & $0.9 \%$ & $1.1 \%$ \\
\hline
\end{tabular}

Note: Percentages may not total $100 \%$ because of rounding and in the later years because of not reported data.

Sources:

U.S. Census Bureau. Table DP-1. Profile of general demographic characteristics, 2000. At: http://censtats.census.gov/data/US/01000.pdf. U.S. Census Bureau. Overview of race and Hispanic origin, 2010. At: www.census.gov/prod/cen2010/briefs/c2010br-02.pdf.

Day JC, U.S. Census Bureau. National population projections. At: www.census.gov/population/www/pop-profile/natproj.html.

U.S. Census Bureau. Table 1. United States—race and Hispanic origin: 1790 to 1990. At: www.census.gov/population/www/

documentation/twps0056/tab01.pdf.

All accessed: December 1, 2011.

disadvantaged and/or minority groups and those with special health care needs as well as children have disproportionate amounts of oral disease and are more likely to face problems when accessing oral health care services. Today, more than a decade later, we see little diminution of the need for care across those same population groups who remain underserved. Health disparities are complex in origin, and they are poignant when considered from the perspectives of those who are chronically in need, often in pain, and yet still without the ability to access the services they need. Dental educators as well as practicing dentists bear a major responsibility for addressing the needs of underserved patients; indeed, health care professionals should feel compelled to rededicate their educational and instructional efforts to the development of a realistic and effective curriculum of care, a curriculum aimed at improving oral health for all. Without substantial change in the training of dental students - and without attention to whom we train as well as the content of their training-dentistry as a profession will only reproduce rather than address and change the current landscape of oral health disparities.

The objectives of this article are to, first, describe the oral health-related situation of the population groups who are experiencing disparities in oral health; second, discuss the ways in which dental education can optimally address these issues in the future; and, third, conclude with a reflection on the past and future contributions of the $J D E$ in meeting these goals. In achieving these objectives, we examine the shifting demographics in the United States from a predominantly white to a majority non-white society, or a "minority majority," as it sometimes is termed. We examine the patterns of need and demand for oral health care as they are affected by these and other variables. And we ask this question: How will allied, predoctoral, and advanced dental students be prepared to meet the health care needs of this changing society? The answer to this question is substantially altered when appropriate consideration is given to patients' socioeconomic status, race/ethnicity, cultural background, ability status, education, and factors related to age.

Approaches for training dental care providers to serve underserved patient populations also require considering the oral-systemic orientation to care and the role of Medicaid, as well as the special needs created by oral health literacy challenges and other ways in which underserved groups may not respond in expected ways to the health care system and its recommendations. The fact that we are educating future professionals who will care for patients from many different races and ethnicities requires the development of cultural competence and also suggests the value of creating primary care commitments to oral health care. Moreover, future dental care providers will need to be willing and able to competently treat patients with special health care needs in the best possible way and to realize the value of interprofessional patient care. They will need to have the skills to function in interprofessional settings, including those designed for children and the elderly. Research has found that dental education has a clear and abiding influence on future providers' professional attitudes 
and behaviors related to providing care for patients from diverse populations. ${ }^{5-10}$ As we move through the twenty-first century, dental educators will remain responsible for ensuring that future providers are optimally prepared to respond to the new challenges of prevention and care that new and larger underserved populations represent. So overwhelming have the needs of the underserved and unserved become that these should now be considered the primary demands for oral health care.

The oral health status of a nation, in all of its parts, will be a direct outcome of the dedication to which we have devoted our skills and talents in addressing the issue of education for these new demands. The $J D E$ has a significant role to play in documenting the progress and in communicating the best of efforts made to meet the challenges ahead. In the next sections, we turn to a description of the oral health care needs of the four groups identified in the 2000 surgeon general's report: 1) persons from socioeconomically disadvantaged groups; 2) groups culturally different from the majority, by virtue of race or ethnicity; 3) patients with special health care needs - sometimes multiple needs, defined in terms of physical, cognitive, psychological, and/or social conditions that define abilities; and finally, 4) the concerns of children. ${ }^{4}$ We describe these population groups and reflect on the implications for dental education, offering suggestions for changes and innovation in instructional/educational approaches that will be critical for ensuring that the documented disparities will be met.

\section{Socioeconomic Disparities and Oral Health Care}

Of the four patient groups named by the U.S. surgeon general in 2000 as having disproportionate amounts of oral disease and serious challenges in accessing oral health care services, the largest is comprised of patients from lower socioeconomic backgrounds or those living in poverty. The official U.S. poverty rate, based on income thresholds issued yearly by the Census Bureau, usually serves as the standard for identifying which citizens fall into this category. ${ }^{11}$ The published thresholds specify the annual cash income minimally required to support families of different sizes. For example, the 2010 poverty threshold for a person living in a single person household and being under sixty-five years of age was $\$ 10,458$, while it was $\$ 22,113$ for two adults and two children in a household. Over the past seventy-five years, the percentage of those living in poverty has fluctuated from 22.4 percent in the late 1950s to the lowest point of 11.1 percent in 1973 ; it was 15.3 percent in 2010 .

Using the overall poverty rate alone to identify socioeconomic condition, however, can mask the fact that different racial/ethnic groups and persons in different age cohorts can have significantly higher poverty rates. For example, in 2010, 27.4 percent of African Americans and 26.6 percent of Hispanics were living in poverty, compared with 9.9 percent of non-Hispanic whites and 12.1 percent of Asian Americans. ${ }^{12}$ Poverty rates in 2010 were highest for families headed by single women, particularly if they were African American or Hispanic: 31.6 percent of households headed by single women were poor, and 15.8 percent of households headed by single men were poor, compared with 6.2 percent of married couple households. While children were 24 percent of the total population, they represented 36 percent of the poor. In 2010, 22.0 percent, or 16.4 million, children were poor; this percentage again differed substantially for children in different racial/ethnic groups. The percentages of children living in poverty in 2010 were as follows: 38.2 percent for African American children, 35 percent for Hispanic children, 34 percent for American Indian children in 2009, 13.6 percent for Asian American children, and 12.4 percent for white non-Hispanic children. ${ }^{11-13}$

For many dental patients living in poverty, the first and often overwhelming question concerning utilizing oral health care services is how they can afford it. The answer is in most cases by ensuring they are covered by Medicaid. Medicaid is a joint federal and state government-run program found in Titles XVIII and XIX of the Social Security Act that is intended to pay specific health care costs for eligible, low-income individuals. ${ }^{14}$ It is the largest source of funding for health-related services for the poorest citizens and allows those who normally would be unable to afford health care to receive medical and dental benefits so long as they satisfy certain requirements. ${ }^{15}$ Both Medicaid and Medicare programs were signed into law by President Johnson on July 30, $1965 .{ }^{16}$ Each state follows federal guidelines but establishes its own Medicaid program and controls eligibility, length, and rate of payment for all services and the type of dental coverage patients on Medicaid can receive. However, even if children and adults are 
covered by Medicaid for certain procedures, they can still face severe challenges when trying to utilize dental services because not all dental providers accept patients with Medicaid coverage. In 2007, only about 26.7 percent of dentists who responded to a survey administered by the American Dental Association (ADA) reported that they treat Medicaid patients. ${ }^{17}$ The surgeon general's report on oral health was quite correct in pointing out that eligibility for Medicaid does not ensure enrollment and that being enrolled in Medicaid does not ensure that patients have access to the needed care. ${ }^{4}$

Why would dentists not accept patients covered by Medicaid? The most commonly given reasons are low reimbursement rates and practice management issues. In 2007, the ADA president stated publicly that reimbursement rates were low and often did not cover the dentists' overhead, a statement that may have served to further discourage already low-participating dentists from treating Medicaid patients..$^{18}$ Even specialist practitioners agreed that low reimbursement fees were a major problem. ${ }^{19}$ Increasing fees, therefore, would appear to have a potentially positive effect on the percentage of dentists who accept patients on Medicaid, as recently seen in Indiana. ${ }^{20}$ In addition to the level of reimbursement, timeliness of reimbursement often has been named as a reason for nonparticipation. Practice management-related concerns, such as higher percentages of Medicaid patients who miss or cancel appointments or are late, also have been cited as reasons for not accepting patients covered by Medicaid. ${ }^{21}$ Finding solutions to the concerns and problems cited by dentists who have chosen not to accept Medicaid payments, therefore, could be a major factor in addressing disparities in treatment. It is important to note also that there are many individuals living in poverty who may not access Medicaid because of the threat they believe it represents to their undocumented residency status; regardless of state rules about the need for documentation, many do not wish to risk the potential consequences. ${ }^{22}$

We believe that dental education can play an important role in increasing the access to dental care for Medicaid patients. Smith et al. showed in 2006 that dental education about providing care for patients on Medicaid was clearly related to professional attitudes and behavior of dental students and general dentists concerning treatment for Medicaid patients. ${ }^{7}$ Brown and Inglehart reported that the same relationship can be found when surveying orthodon- tists, ${ }^{8,9}$ and Garfinkle at al. provided support for the important role of dental education in this context in a survey of periodontists. ${ }^{10}$ Recently, Valentine and Inglehart reported that personal experiences with family members or friends on Medicaid before entering dental school, as well as experiences during dental school, can have an effect on how comfortable dentists are when treating Medicaid patients. ${ }^{15}$ Providing dental and dental hygiene students with focused classroom-based, clinical, and communitybased educational experiences can therefore improve students' attitudes towards providing care for patients on Medicaid and increase their willingness to treat these patients..$^{7-10,23}$ Including in the curriculum an introduction to the Medicaid program and a more in-depth look at its importance within the context of the data on poverty presented above is essential.

A related, and seldom-taught, aspect of underserved populations is the role of oral health literacy in seeking and following through with oral health care, especially for patients in socioeconomically disadvantaged conditions. Patients' oral health and their missing appointments or being late for appointments might be related to the level of their understanding of the health care system and to how well the dental office staff communicates with them. ${ }^{24}$ Health literacy has been defined as "the degree to which individuals have the capacity to obtain, process, and understand basic health information and services needed to make appropriate health decisions. ${ }^{~}{ }^{25}$ Research has found that poor literacy skills affect many aspects of life, including the general health of individuals and their children. ${ }^{26,27}$ For example, 43 percent of U.S. adults are not able to accurately use printed materials that relate to health, safety, or personal finances. A survey concerning English literacy found that 80 million U.S. adults are unable to refer to materials such as ingredient lists or tables cataloging age, blood pressure, and physical activity. ${ }^{28}$ Given that individuals with less education and those from minority racial/ ethnic groups are more likely to have lower health literacy, dental and dental hygiene students should be learning communication skills to address these issues. For example, using visual information can be crucially important ${ }^{24}$ for some individuals, although the standard approach is for the health care provider to simply "talk at" the patient.

In summary, educating future providers in dental schools and allied and advanced dental programs has to centrally focus on ensuring solid educational programs concerning providing care for patients 
from lower socioeconomic backgrounds. Raising awareness and providing knowledge about the oral health-related challenges these patients face on a daily basis can begin in the classroom, but need to be accompanied by explicit clinical education and skills training in community-based educational settings.

\section{Special Health Care Needs and Oral Health}

The surgeon general's report on oral health described patients with special health care needs as one patient group with a disproportionately high level of oral disease and difficulties with accessing oral health care services. ${ }^{4}$ A definition provided by the Special Care Dentistry Association identifies these patients as having "physical, medical, developmental, or cognitive conditions." 29 According to the American Community Survey in 2006, 5.1 percent of the civilian non-institutionalized U.S. population over four years of age (about 41.3 million people) self-reported having a disability. Commonly reported disabilities were physical (9.4 percent), sensory (4.3 percent), mental (5.8 percent), and self-care disabilities (3 percent). While younger cohorts had a lower prevalence rate (6.3 percent for five to fifteen years), the oldest cohort of sixty-five years of age and over had the highest percentage (41 percent) of persons with a disability. ${ }^{30}$ Overall, more than 50 million individuals in the United States, or roughly one in five, currently have at least one disability. ${ }^{31}$ Given the estimate that, by 2030, one in five adults in this country will be at least sixty-five years of age, ${ }^{32}$ we can expect a significant increase in the numbers of patients with special needs in the coming decades. The "elderly" (over sixty-five years) and the "old old" (over eighty years) bring to their oral care needs a variety of special considerations..$^{33}$ They tend to have multiple medical problems and conditions, with the accompanying multiple medications that also complicate oral health needs and treatment. Moreover, many are place-bound, living without access to transportation to health care facilities or without the ability to physically manage that transport.

Major efforts to improve dental students' education about treating special needs patients occurred in the 1970s, when the Robert Wood Johnson Foundation gave four-year grants to eleven U.S. dental schools for the development of teaching programs for patients with "handicapping" conditions. ${ }^{34}$ At about the same time, the American Association of Dental Schools (AADS; the predecessor of the American Dental Education Association, ADEA) published curriculum guidelines for educating predoctoral students about treating these patients. ${ }^{35}$ Despite those efforts, a 1993 survey of U.S. and Canadian dental schools showed that the coverage of this material in predoctoral curricula varied and was largely insufficient. ${ }^{36,37}$ Moreover, a follow-up survey in 1999 documented a decrease in the time spent in the predoctoral dental curriculum on the topic of special needs patients. ${ }^{38,39}$

In apparent acknowledgment of this situation, the Commission on Dental Accreditation (CODA) in 2004 adopted new standards for dental and dental hygiene programs to ensure that all programs provide education about these issues. ${ }^{40}$ The ADEA House of Delegates adopted Resolution 18-H-2004 at their annual meeting that same year. ${ }^{41}$ On January 1 , 2006, the adopted revision of CODA Standard 2-18 was implemented; it states that "Graduates must be competent in assessing the treatment needs of patients with special needs." The intent statement specifies that "Clinical instruction and experiences with patients with special needs should include instruction in proper communication techniques and assessing the treatment needs compatible with the special need."

Although clear action was taken to address the need for education in special needs dentistry, it seems that the response to that action fell short of expectations. In 2008, Dehaitem et al. explored the question for U.S. dental hygiene programs. ${ }^{42}$ They surveyed 102 dental hygiene programs (49 percent) and found that nearly all (98 percent) addressed this topic in lectures, but that only 42 percent required their students to gain clinical experiences with patients with special needs. In 2009, Krause et al. followed up on the Dehaitem et al. study and collected data from twenty-two dental schools in the United States and Canada ${ }^{43}$ These authors found that 91 percent of the schools covered this topic in the clinical education curriculum, but that only 64 percent offered a separate course about special needs patients. This study also found that both the approaches used to educate students about these issues and the specific special needs addressed differed widely. A survey of dental students in fourteen schools supported these findings. ${ }^{44}$

An assumption underlying standards, such as those of CODA, is that these changes will contribute to reducing the disparities in oral health and access to oral health care that patients with special needs have 
experienced in the past. In fact, this assumption has been supported by research with general dentists as well as with orthodontists and periodontists. Dao et al. found that the more general dentists agreed with statements that their dental education had prepared them well to treat patients with special needs, the more likely they were to actually treat these patients and to have staff members who were comfortable and knowledgeable about providing such care. ${ }^{5}$ Brown and Inglehart ${ }^{8,9}$ and Garfinkle et al. ${ }^{10}$ published data suggesting that the same relationship between dental education and professional attitudes and behavior concerning patients with special health care needs exists among orthodontists and periodontists.

In consideration of these findings, it is worth exploring how students might be optimally trained to provide the best possible care for these patients. We suggest a "bottom up/top down" approach that educates future providers from the bottom up about the special need/disability at hand and then analyzes from the top down which specific challenges and issues arise when treating the patient. Knowledge and awareness of the unique characteristics of a certain disability can then be used to skillfully address the concrete issues at hand. One example is the work by Weil and Inglehart who explored issues related to providing care for patients with Autism Spectrum Disorders (ASD). ${ }^{45-47}$ These authors described the unique characteristics of these patients and the wide range of severity of symptoms. After becoming aware of these patients' issues and gaining knowledge about these special needs, future providers will more likely have a clear understanding of responses that would be appropriate when encountering a patient with an ASD. Clinical skills training then consists of connecting this bottom-up understanding with the top-down analysis of the concrete problems that arise when patients are encountered in the clinical setting.

A final consideration concerning the education of dental professions students about treating patients with special health care needs is the superiority of an interprofessional team of providers if treatment is to be optimal. Although this approach is well accepted when providing care for patients with craniofacial anomalies, ${ }^{48}$ it should be a fact of life when treating all patients with special needs-whether the concerns reflect medical issues such as diabetes, ${ }^{49}$ mental health issues such as depression, ${ }^{50}$ or a range of cognitive/developmental issues. ${ }^{45-47}$

Because medical care for individuals with special needs has improved so dramatically and people are living longer with a range of health conditions, the percentage of patients with special health care needs can be expected to grow over the next decades. Educating students in the dental health professions about providing optimal care for these patients, therefore, is gaining importance. Opportunities for interprofessional collaborations in this area are crucial for providing the best possible care for these patients.

\section{Oral Health of Children}

Children comprised one of the four groups of underserved patients mentioned in the 2000 surgeon general's report. ${ }^{4}$ The report drew attention to the fact that dental caries is the most common chronic childhood disease in the United States, being five times more common than asthma, seven times more common than hay fever, and twenty times more common than diabetes. ${ }^{4,51}$ While the prevalence of caries has significantly decreased over the past decades for most age cohorts, a report by the Centers for Disease Control and Prevention (CDC) in 2007 showed that the percentage of young children between two and five years of age with caries actually increased from 18 percent in 1988-94 to 24 percent in 1999-2004. ${ }^{52}$ In addition, children in socioeconomically disadvantaged groups are disproportionately affected by caries. The third National Health and Nutrition Examination Survey found, for example, that nearly 80 percent of two- to five-year-olds living at or below the poverty level had experienced caries. ${ }^{53}$

Caries in young children has a number of serious consequences. Caries in the primary dentition is a significant predictor of caries in the permanent dentition $^{54,55}$ and a major reason for emergency room visits. ${ }^{56}$ Impaired oral health can cause insufficient development in children who have no other medical problems and can affect their weight and height. ${ }^{57,58}$ It also affects children's school attendance and the number of days with restricted activity and can result in substantial levels of work loss for the parents/guardians who take care of these children. ${ }^{59,60}$ Impaired oral health-related quality of life is a clear consequence of poor oral health. ${ }^{61,62}$ Research has even shown that caries affects children's smiling patterns and thus potentially their social interactions. ${ }^{63}$

One reason for the large percentages of children with poor oral health is the shortage of general dentists who provide dental care for children, and especially children covered by Medicaid. ${ }^{64}$ This situation is likely to become even worse over the next decade if the projections of the U.S. Census 
Bureau concerning the increase in the number of children under fifteen years from 1993 to 2020 and the predictions of ADEA concerning the numbers of dentists entering and leaving the workforce between 2000 and 2020 are correct. ${ }^{65}$ While pediatric dentists provide a large amount of oral health care for children and a disproportionately higher percentage for patients with Medicaid, ${ }^{66}$ their numbers are small. But despite the increased demand for pediatric dentists, their numbers have not increased sufficiently. The American Academy of Pediatric Dentistry (AAPD) reported that, in 1990, 3,967 pediatric dentists were practicing in the United States ${ }^{67}$ and that this number had decreased to approximately 3,650 by 1998 . Efforts were made to increase the number by adding new pediatric dental residency programs and increasing the number of residents in current programs. As a result of these efforts, Casamassimo et al. reported that there were 5,513 professionally active pediatric dentists in $2006 .{ }^{68}$ Unfortunately, if the caries rate continues to remain high, even this increase will not be sufficient to ensure that all children, and especially children covered by Medicaid, have access to desperately needed oral health care. Dental education, therefore, has an obligation to focus on educating future primary care dentists in ways that create a strong commitment to treating and preventing oral disease in children.

Essential for the prevention of oral disease are programs that provide an early start to both good home care and appropriate professional care. The AAPD, in 1986, adopted guidelines on Infant Oral Health (IOH) Care as a way to promote oral health and prevent oral disease in very young children. ${ }^{69}$ This policy has since been revised, but continues to emphasize the importance of establishing a dental home early on and having a first dental visit as soon as the first tooth erupts or at the child's first birthday. A survey of 2,157 AAPD members in 2007 found that the majority agreed with the AAPD policy concerning infant oral health examinations and reported that they performed $\mathrm{IOH}$ exams. ${ }^{70}$ However, only 53 percent of the respondents indicated that they saw infants aged twelve months or younger, and not all engaged in oral hygiene education for their patients' parents..$^{70} \mathrm{~A}$ follow-up study with general dentists found that they were much less likely to treat infants and toddlers and had more negative attitudes towards these types of examinations than pediatric dentists. ${ }^{71}$ In addition to emphasizing the importance of early establishment of a dental home, the AAPD has ad- vocated for involving allied health professionals, community organizations, and other health professionals in efforts focused on preventing oral disease in young children and on educating parents about the importance of good oral health for their child's well-being. ${ }^{69}$ Projects at oral health disparities centers in Boston, Denver, and San Francisco funded by the National Institute of Dental and Craniofacial Research are conducting rigorous testing of promising approaches to prevention of Early Childhood Caries (ECC). ${ }^{72}$ The results will help structure educational content and approaches that should be considered integral parts of ECC prevention education for all dental professionals.

Strong efforts to increase interprofessional education and collaboration are needed in this area as well. The findings related to $\mathrm{IOH}$ exams and other efforts beg a number of clinical education and continuing education questions in terms of the needs of this vulnerable population group and their caregivers.

In summary, it is essential to increase the effectiveness of clinical education concerning establishing professional patterns and practices for care and prevention of oral disease in children. Education aimed at changing attitudes and behavior concerning providing care for children can be expected to shape much-needed commitments to prevention and early care. ${ }^{6}$ Additionally, special attention needs to be given to increase educational efforts focusing on dentists' collaborations with allied dental professionals and other health professionals.

\section{Cultural Diversity: Culture, Race, Ethnicity, and Oral Health}

Table 1 shows that significant changes in the racial/ethnic composition of the U.S. population have occurred over the past decades and are predicted to continue in the future. CODA Standard 2-17 appropriately acknowledges these changes in asserting that graduates must be "competent in managing a diverse patient population and have the interpersonal and communications skills to function successfully in a multicultural work environment." ${ }^{40}$ The question for our dental educational institutions, of course, is how educational efforts can ensure that graduates of dental, dental hygiene, and advanced dental education programs are culturally competent providers. 
Figure 1 is a framework for developing answers to this question. When educating future providers about interacting with patients from diverse groups, one of two general strategies can be used. First, multiple efforts can be made to educate students about each racial/ethnic group separately and describe how each is different from or similar to the currently still majority culture of European Americans (see the Darby and Walsh texbook ${ }^{73}$ as an example of such an approach). Given the tremendous variability of individuals even in distinct ethnic groups, this approach has two clear dangers. It tends to suggest generalizations and stereotypes that are not helpful and that represent an ethnocentric majority approach. Further, such an approach reflects "we vs. they" attitudes that can be divisive or disrespectful, thereby hindering efforts to embrace diversity as a valuable aspect of our society. A second model, the so-called General Relations or Multicultural Model, was introduced by Inglehart and Tedesco in $1997 .{ }^{74}$ Figure 1 shows that this model focuses on challenging students to understand their own personal, social, and cultural backgrounds and how their individual characteristics affect the way they think and feel about the world and interact with others. Gaining a deeper understanding of how their own culture and experiences affect their relationships and communication with others, who may be shaped by different experiences and other cultural backgrounds, can stimulate a more comprehensive awareness of the complexity of cross-cultural interactions. This kind of awareness provides the foundation for gaining the skills necessary to be a successful provider in a diverse society.
Adopting the General Relations Model as a basis for educational interventions requires addressing a number of questions about specific strategies in educational environments that might be most successful in educating culturally competent providers. Reflecting on the "who," "what," "when," and "how" for educating our students can provide some insights into this complex dynamic.

Deciding "who" should be involved in educational efforts of this type focuses attention on the need for creating racial/ethnic and cultural diversity among both student bodies and groups of faculty and staff members and administrators in dental schools and dental hygiene programs. The fact that underrepresented minority students, providers, and faculty and staff members are still "missing persons" in the health professions ${ }^{75}$ has to raise concerns. Research has found that being educated in a diverse classroom setting allows European American students to gain a better understanding of the complexity of racial issues in U.S. society. ${ }^{76-78}$ Valentine and Inglehart ${ }^{15}$ provided clear evidence of the role of personal, as well as professional, experiences in shaping students' attitudes and comfort levels when interacting with patients from underserved groups. Increasing the numbers of underrepresented minority students is therefore an important, perhaps the best - but certainly the most natural- way to ensure that education develops students' cultural competence. Woolfolk and Price ${ }^{79}$ offer a comprehensive analysis of these issues in their contribution to this issue of the JDE. Increasing numbers of role models who are faculty and administrators from diverse backgrounds adds

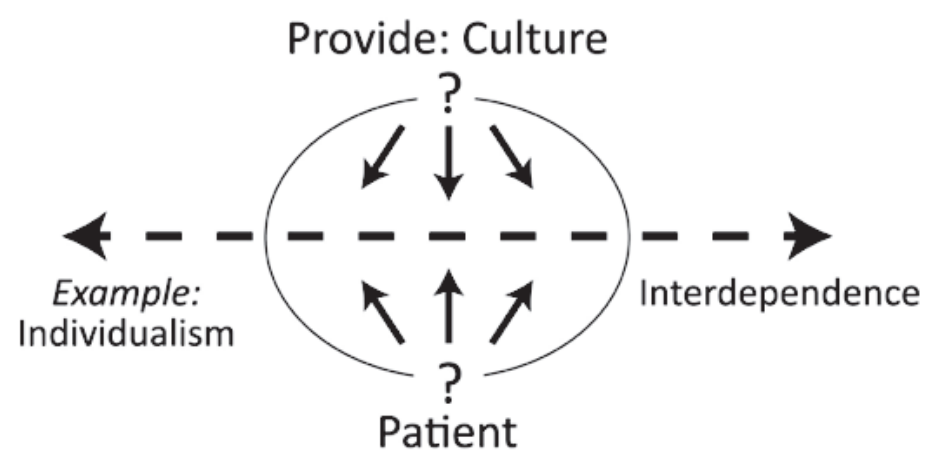

Figure 1. A multicultural approach to patient care 
still more critical support to efforts to increase the cultural competence of students. Drisko ${ }^{80}$ expands on this consideration in her reflections on the situation of faculty members in U.S. dental schools in her contribution to this issue.

In addition to considering who needs to be involved, of course, the question of "what" needs to be taught must be considered. Along with basic facts about historical developments and social issues that can be presented in classroom settings, it is essential that instruction move into clinical settings to develop students' cross-cultural communication skills. Communication breakdowns and problems with language barriers in clinical settings are powerful learning moments that can be used to increase students' awareness, their understanding and expertise in caring for patients from diverse groups, and ultimately, their commitment to providing care for all patients, regardless of their backgrounds. In addition, community-based education can offer the optimal venue for learning more about working in a diverse environment.

The question of "when" these educational efforts should begin is ideally answered, quite simply, as "on Day 1" of the students' dental or dental hygiene education. One excellent example of this approach can be found at the School of Dentistry and the Dental Hygiene Program at the University of Michigan. Since 1994, these programs have offered orientation experiences focused on "Building a community in times of diversity" and "Treating diverse patients" to all incoming students. On the second day of their enrollment, dental students participate in a workshop about cross-cultural communication in the morning and then leave at noon by bus for a visit to the African American History Museum in Detroit. Their assignment is to discuss in small groups how the historical situation of racial groups in the United States shapes patients' attitudes and behaviors. Following their visit, the students participate in a debriefing session. After participating in a second workshop, they visit the Farmington Hills Holocaust Memorial or the Arab American Museum in Dearborn, MI. Again, the students meet in small groups to discuss and reflect on the implications of what they have seen and then participate in a debriefing session on the next day. Including these two programs during the orientation sessions as the first steps in their professional education alerts students to the fact that diversity is taken seriously in this educational environment. It goes a long way to establish the realization that becoming a culturally competent provider is one of the main objectives of their educational experience.

The final specific question is concerned with "how" education related to providing care for diverse patients should be structured. One answer is found in a study by Richards and Inglehart, who showed that an interdisciplinary approach to case-based teaching increased students' awareness about the importance of factors related to cultural diversity and affected their making a diagnosis and treatment planning. ${ }^{81}$ In this regard, too, the power of experiential learning in clinics and community settings cannot be underestimated. It also needs to be emphasized that cultural diversity does not merely relate to patients' race or ethnicity. Factors such as patients' sexual orientation play an essential role in this context as well and need more attention in dental and dental hygiene curricula. ${ }^{82}$

Finally, before leaving the question of how education can meet the needs of a changing population, we are compelled by current developments to suggest that the historically slow response of our educational institutions, as well as the dental profession itself, may well result in what has been described as "disruptive innovation" 83 in the form of a new provider developed explicitly to care for those who are underserved or unserved by the current professional model and training. The DHAT experience in Alaska came about because the unmet dental needs of Alaska Native people eventually demanded a new response, and in spite of criticism from the profession and from many dental educators, the effectiveness of the model has been demonstrated. ${ }^{84}$ Notwithstanding legislation designed to limit the expansion of such programs, a growing expression of the needs of the oral health care disadvantaged foreshadows an inevitability regarding the incorporation of mid-level oral health providers into the health care system. A supplemental issue of the Journal of Public Health Dentistry in spring 2011 was devoted to the development of this approach, and in November 2011, the W.K. Kellogg Foundation sponsored a national conference on "Legacy and Innovation: Improving Oral Health for All Children." At that conference, the voices of many of the underserved groups described in this article were heard-most notably perhaps those of American Indians whose plight was reflected in a recent report on the status of oral health on reservations..$^{85}$ We must expect that other vulnerable groups and their advocates also will demand a response to their needs. 
Whether or not a given dental school commits to the education of mid-level providers, dental educators have a responsibility to respond to the needs that a growing constituency believes will best be met in this way. That means engaging the educational issues that are represented by this model, by the growing focus on interprofessional education, and by any model that promises to meet the growing oral health needs of a transformed population.

\section{Conclusions and Outlook}

Our title suggested a review of the changes in demand for dental care as a function of the disparities of population groups and the implications of those changes for dental education. Following the lead of the surgeon general's report in $2000,{ }^{4}$ the focus was on those four patient groups that have disproportionate amounts of dental disease and encounter challenges in accessing dental care. For each of the four groups, an overview of the current status and some historical considerations were provided, followed by recommendations of ways in which dental educators can contribute to improving responses to the challenges represented by ensuring care for patients from these underserved groups. We have asserted that dental, allied, and advanced dental education shapes future providers' professional attitudes and behavior concerning providing care for these underserved patients. ${ }^{5-10,15,46}$ The current CODA standards clearly state that dental and dental hygiene education needs to prepare future providers in ways that ensure the graduates will be "competent in managing a diverse patient population and have the interpersonal and communications skills to function successfully in a multicultural work environment" (Standard 2.17) and that they are "competent in assessing the treatment needs of patients with special needs" (Standard 2.18) ${ }^{40}$ The new CODA standards that will be implemented on July 1, 2013, only strengthen these commitments. ${ }^{86}$ Clearly, major educational efforts should focus on ensuring that these standards are met.

Figure 2 suggests a model that could serve as a framework for considering how to meet the standards related to "special needs"-including all of the needs of population groups that are unserved, underserved, or experiencing higher rates of oral disease or difficulty in gaining adequate treatment. ${ }^{87}$ It postulates that dental educators need to have awareness, skills, and knowledge concerning oral health disparities if they are to educate their students in such a way that these future providers have the necessary commitment, as well as the understanding and expertise that can result in the changes needed to improve the oral health of all. Well-prepared dental providers will view working with patients from these underserved groups not as problems, but as rewardingly diverse in the professional challenges they present.

Commitment to rearranging financial structures and reforming educational practices will be needed to situate and animate the framework described above, if we are to fulfill its promise and to sustain the "who, what, when, and how." Treating and preventing health disparities in the full context of oral and systemic connections are fundamental to the integrity of what is needed to advance the professional preparation of oral health care providers. Educational experiences with curricular emphasis on health disparities and related clinical community-based train-
INSTRUCTORS

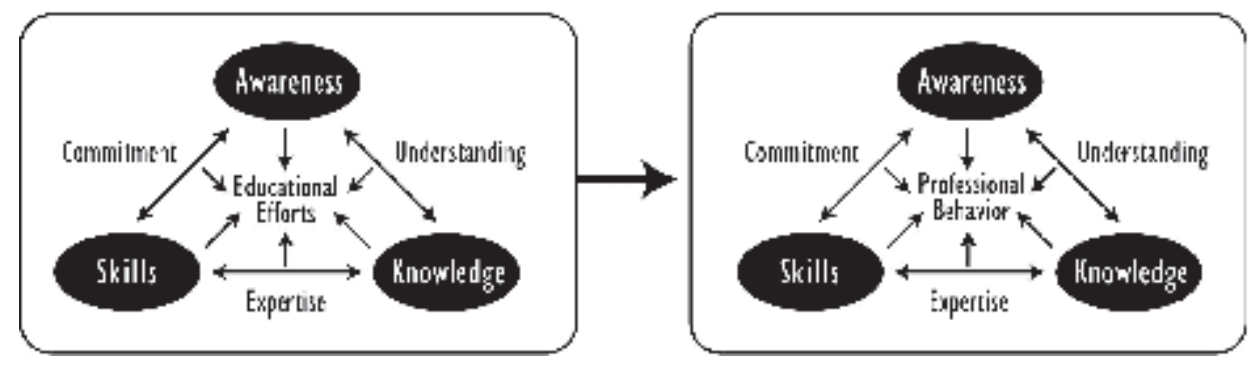

Figure 2. A humanistic model of professional education 
ing are essential to moving forward. In addition, a more complete and contemporary understanding is needed for access to care and its relationship to race, difference, and the intersection of social and economic class. Two major educational program efforts, the Macy Study ${ }^{88}$ and the Pipeline, Profession, and Practice: Community-Based Dental Education program, ${ }^{89}$ both led by Formicola and Bailit over the last decade, provide ample guidance as vehicles for continued change and have been well described in the $J D E$. Both efforts were data-driven, analytically framed with full aim at changing educational practices and preparation based on broader context and representation for the reach of the curriculum, clinical training, and diversity of our students. Both efforts were made possible with major funding from leading foundations committed to addressing oral health disparities and diversity in the health professions - foundations that value the promise of the dental profession's role for the demands and needs before us. In keeping with marking history in research and preparation for practice, it continues to be dental education's responsibility to deliver on the promise.

Acknowledging that this article is included in this anniversary issue of the $J D E$, we will also reflect briefly on the role this journal has played in dental education over the past seventy-five years and on the role it can play in the future. While the journal was seldom named directly in the past pages, a look at the reference list shows that this article could not have been written without the information the $J D E$ has published. This journal offers investigators and educators opportunities to inform others about what is occurring and to share innovations and trends in education. It encourages the identification of challenges and the sharing of best practices with readers. It moves dental education along by providing a forum for discussions of new developments and sharing information about dental education outside North America. It enriches the intellectual debate among dental educators and administrators, as this anniversary issue clearly will attest.

This article is intended as a call to action for dental educators, academic leaders, and administrators to acknowledge the greatest challenge before us and before the dental profession: that of meeting the demand for prevention and treatment of oral disease across a spectrum of groups who have not yet realized the benefits of the advanced techniques and treatment modalities with which the more affluent, well-insured, and easier-to-treat among us are well acquainted. It is a call to professionals-whether clinicians, educators, or researchers-to prevent another outcome as in the case of Deamonte Driver, a boy who died in 2007 as a result of inadequate dental care. ${ }^{90}$ It causes us to reflect on how we can best and most responsibly educate our students, ensuring that they are keenly aware of the needs of underserved patients and why these needs exist and that they have a range of skills and a solid foundation of knowledge and experience across a range of settings, from community clinics to private dental offices, that will allow them to make a difference not just for some, but for all patients in need of oral health care.

\section{REFERENCES}

1. Wendell Cox Consultancy/Demographia. U.S. population from 1900 (statistics from U.S. Census Bureau). At: www.demographia.com/db-uspop1900.htm. Accessed: November 14, 2011.

2. Rosenberg M. Current U.S.A. population. At: http://geography.about.com/od/obtainpopulationdata/a/uspopulation. htm. Accessed: November 14, 2011.

3. U.S. Census Bureau. Aging boomers will increase dependency ratio, census bureau projects: older American population to become more diverse. At: www.census.gov/ newsroom/releases/archives/aging_population/cb10-72. html. Accessed: November 14, 2011.

4. Oral health in America: a report of the surgeon general. Rockville, MD: U.S. Department of Health and Human Services, National Institutes of Health, National Institute of Dental and Craniofacial Research, 2000.

5. Dao LP, Zwetchkenbaum S, Inglehart MR. General dentists and special needs patients: does dental education matter? J Dent Educ 2005;69(10):1107-15.

6. Rich JP III, Straffon L, Inglehart MR. General dentists and pediatric dental patients: the role of dental education. J Dent Educ 2006;70(12):1308-15.

7. Smith CS, Ester TV, Inglehart MR. Dental education and care for underserved patients: an analysis of students' intentions and alumni behavior. J Dent Educ 2006;70(4):398-408.

8. Brown B, Inglehart MR. Orthodontic care for underserved patients: professional attitudes and behaviors of orthodontic residents and orthodontists. Angle Orthod 2011;81(6):1090-6.

9. Brown BR, Inglehart MR. Orthodontists' and orthodontic residents' education about treating underserved patients: effects on professional attitudes and behavior. J Dent Educ 2009;73(5):550-62.

10. Garfinkle AJ, Richards PS, Inglehart MR. Providing care for underserved patients: periodontists' and periodontal residents' educational experiences, attitudes, and behavior. J Periodontol 2010;81(11):1-9.

11. U.S. Department of Health and Human Services. The 2011 HHS poverty guidelines. At: http://aspe.hhs.gov/ poverty/11 poverty.shtml. Accessed: October 16, 2011.

12. U.S. Census Bureau. Income, poverty, and health insurance coverage in the United States: report P60, n. 238, table B-2. Washington, DC: U.S. Census Bureau, 2010:68-73. 
13. Wight VR, Chau M, Aratani Y. Who are America's poor children? The official story. New York: National Center for Children in Poverty, Mailman School of Public Health, Columbia University, March 2011.

14. Hoffman ED Jr, Klees BS, Curtis CA. Overview of the Medicare and Medicaid programs. Health Care Financing Rev: Statistical Suppl 2005;281:283-304.

15. Valentine AE, Inglehart MR. Medicaid patients in dental school clinics: do personal and professional experiences matter? J Dent Educ 2011;75(9):1225-35.

16. U.S. Department of Health and Human Services. Centers for Medicare \& Medicaid Services. At: www.cms.hhs.gov. Accessed: November 14, 2011.

17. American Dental Association Survey Center. Just the facts: Medicaid. ADA News 2009;40(11):1.

18. Medicaid reimbursement for dental care too low, witnesses testify. Medical News Today, April 2, 2007. At: www.medicalnewstoday.com/printerfriendlynews. php?newsid=66614. Accessed: December 1, 2011.

19. Im JL, Phillips C, Lee J, Beane R. The North Carolina Medicaid program: participation and perceptions among practicing orthodontists. Am J Orthod Dentofacial Orthop 2007;132(2):144.

20. Hughes RJ, Damiano PC, Kanellis MJ, Kuthy R, Slayton R. Dentists' participation and children's use of services in the Indiana dental Medicaid program and SCHIP: assessing the impact of increased fees and administrative changes. J Am Dent Assoc 2005;136(4):517-23.

21. Iben P, Kanellis MJ, Warren J. Appointment-keeping behavior of Medicaid-enrolled pediatric dental patients in eastern Iowa. Pediatr Dent 2000;22:325-9.

22. Gold RB. Immigrants and Medicaid after welfare reform. Guttmacher Rep Public Policy 2003;6(2). At: www. guttmacher.org/pubs/tgr/06/2/gr060206.html. Accessed: December 1, 2011.

23. Piskorowski WA, Fitzgerald M, Mastey J, Krell RE. Development of a sustainable community-based dental education program. J Dent Educ 2011;75(8):1038-43.

24. Wang SJ, Briskie D, Hu J, Majewski R, Inglehart MR. Illustrated information for parent education: parent and patient responses. Pediatr Dent 2010;32(4):295-303.

25. Institute of Medicine. Health literacy: a prescription to end confusion. Washington, DC: National Academies Press, 2004.

26. Kutner ME, Greenberg E, Jin Y, Paulsen C. The health literacy of America's adults: results from the $2003 \mathrm{Na}-$ tional Assessment of Adult Literacy. Washington, DC: National Center for Education Statistics, U.S. Department of Education, 2006.

27. Rudd RE. Health literacy skills of U.S. adults. Am J Health Behav 2007;31(Suppl 1):S8-S18.

28. Kiresh IS, Jungeblut A, Jenkins L, Kolstad A. Adult literacy in America: a first look at the results of the National Adult Literacy Survey (NALS). Washington, DC: U.S. Department of Education, Office of Educational Research and Improvement, National Center for Education Statistics, 1993.

29. Special Care Dentistry Association (SCDA). SCDA definitions, policies, and guidelines. At: www.scdaonline. org/?page=Definitions. Accessed: November 14, 2011.
30. Brault M. Disability status and the characteristics of people in group quarters: a brief analysis of disability prevalence among the civilian noninstitutionalized and total populations in the American community survey. February 2008. At: www.census.gov/hhes/www/disability/GQdisability.pdf. Accessed: December 16, 2011.

31. U.S. Census Bureau. American community survey/ Puerto Rico community survey, 2006 subject definitions. At: www.census.gov/acs/www/Downloads/data documentation/SubjectDefinitions/2006_ACSSubject Definitions.pdf. Accessed: December 16, 2011.

32. Lawton L. Providing dental care for special patients: tips for the general dentist. J Am Dent Assoc 2002;133(12):1666-70.

33. Lamster IB, Northridge ME, eds. Improving oral health for the elderly: an interdisciplinary approach. New York: Springer Science and Media, 2008.

34. Campbell JT, McCaslin FC. Evaluation of a dental training program for the care of the handicapped. Spec Care Dent 1983;3(3):100-7.

35. Bentz GS, Lotzkar S. Appendix 11: curriculum guidelines for dentistry for the handicapped. J Dent Educ 1979;43(7):337-41.

36. Fenton SJ. 1993 survey of training in the treatment of persons with disabilities. InterFace 1993;9:1,4.

37. Fenton SJ. Universal access: are we ready? Spec Care Dent 1993;13:94.

38. Fenton SJ. People with disabilities need more than lip service (editorial). Spec Care Dent 1999;19:198-9.

39. Romer M, Dougherty N, Amores-Lafleur E. Predoctoral education in special care dentistry: paving the way to better access? J Dent Children 1999;66(2):132-5.

40. Commission on Dental Accreditation. Accreditation standards for dental education programs. Chicago: American Dental Association, July 30, 2004.

41. American Dental Education Association. Proceedings of the 2004 House of Delegates: Resolution 18-H-2004. J Dent Educ 2004;68(7):705.

42. Dehaitem MJ, Ridley K, Kerschbaum WE, Inglehart MR. Dental hygiene students and patients with special needs: a survey of U.S. programs. J Dent Educ 2008;72(10):1010 9.

43. Krause M, Vainio L, Zwetchkenbaum S, Inglehart MR. dental education about patients with special needs: a survey of dental school programs. J Dent Educ 2010;74(11):1179-89.

44. Vainio L, Krause M, Inglehart MR. Patients with special health care needs: dental students' educational experiences, professional attitudes and behavior. J Dent Educ 2011;75(1):13-22.

45. Weil TN, Bagramian RA, Inglehart MR. Treating patients with autism spectrum disorder: specialists' perspectives. Spec Care Dentist 2011;31(1):817.

46. Weil TN, Inglehart MR. General and pediatric dentists' professional attitudes and behavior concerning patients with autism: does dental education matter? J Dent Educ 2010;74(12):1294-307.

47. Weil TN, Inglehart MR. Pediatric patients with autism spectrum disorders: severity of symptoms and oral health and oral health-related behavior. Pediatr Dent, forthcoming. 
48. Munz SM, Edwards SP, Inglehart MR. Adolescents with cleft lip/palate: quality of life and satisfaction with treatment and treatment outcomes. Int J Oral Maxillofac Surg 2011;40:790-6.

49. Kanjirath PP, Kim SE, Inglehart MR. Diabetes and oral health: the importance of oral health-related behavior. J Dent Hyg 2011;85(4):264-72.

50. McFarland M, Inglehart M. Depression, self-efficacy, and oral health: an exploration. Oral Health Dent Management Black Sea Countries 2010;9(4):214-22.

51. Evans CA, Kleinman DV. The surgeon general's report on oral health: opportunities for the dental professional. J Am Dent Assoc 2000;131(12):1721-8.

52. Dye BA, Tan S, Smith V, Lewis BG, Barker LK, ThorntonEvans G. Trends in oral health status: United States, 1988-94 and 1999-2004. Vital Health Stat 2007;11(248).

53. National Health and Nutrition Examination Survey III, 1988-1994, Series 11, nos. 1 and 1a. Atlanta: National Center for Health Statistics, 1997.

54. O'Sullivan DM, Tinanoff N. The association of early dental caries patterns with caries incidence in preschool children. J Public Health Dent 1996;56(2):81-3.

55. Al-Shalan TA, Erickson PR, Hardie NA. Primary incisor decay before age 4 as a risk factor for future dental caries. Pediatr Dent 1997;19(1):37-41.

56. Sheller B, Williams BJ, Lombardi SM. Diagnosis and treatment of dental caries-related emergencies in a children's hospital. Pediatr Dent 1997;19(8):470-5.

57. Willershausen B, Haas G, Krummenauer F, Hohenfellner $\mathrm{K}$. Relationship between high weight and caries frequency in German elementary school children. Eur J Med Res 2004;9(8):400-4.

58. Napoles B, Arruda AO, Inglehart MR, Sohn W. Children's oral health and nutritional intake in rural Brazil. Presentation at International Association for Dental Research, Toronto, Canada, July 2008.

59. Gift HC, Reisine ST, Larach DC. The social impact of dental problems and visits. Am J Public Health 1992;82(12):1663-8.

60. Jackson SL, Vann WF, Kotch JB, Pahel BT, Lee JY. Impact of poor oral health on children's school attendance and performance. Am J Public Health 2011;101(10):1900-6.

61. Inglehart MR, Filstrup SL, Wandera A. Oral health-related quality of life and children. In: Inglehart MR, Bagramian RA, eds. Oral health and quality of life. Chicago: Quintessence, 2002.

62. Filstrup SL, Briskie D, da Fonseca M, Lawrence L, Wandera A, Inglehart MR. Early childhood caries and quality of life: child and parent perspectives. J Pediatr Dent 2003;25(5):431-40.

63. Patel RR, Tootla R, Inglehart MR. Children's smiling patterns: a function of oral health? Community Dent Oral Epidemiol 2007;35:44-52.

64. Pew Center on the States. The cost of delay: state dental policies fail one in five children. Washington, DC: Pew Center on the States, February 2010.

65. Valachovic RW. Dental workforce trends and children. Ambul Pediatr 2002;2(2 Suppl):154-61.

66. Nainar SMH, Tinanoff N. Effect of Medicaid reimbursement rates on children's access to dental care. Pediatr Dent 1997;19(5):315-6.
67. American Academy of Pediatric Dentistry. Policy on workforce issues and delivery of oral health care services in a dental home. Pediatr Dent 2011;33:26-30.

68. Casamassimo P, Berlocher WC, Cheney W, Donly K, Lee J, Nowak A, et al. The future of pediatric dentistry advanced education: the need for change in training standards. Pediatr Dent 2009;31(4):298-309.

69. American Academy of Pediatric Dentistry. Guideline on infant oral health care. Pediatr Dent 2006-07;28(7 Suppl):73-6.

70. Malcheff S, Pink TC, Sohn W, Inglehart MR, Briskie D. Infant oral health examinations: pediatric dentists' professional behavior and attitudes. Pediatr Dent 2009;31(3):117-24.

71. Ananaba N, Malcheff S, Briskie D, Inglehart MR. Infant oral health examinations: general and pediatric dentists' attitudes and professional behavior. J Mich Dent Assoc 2010;92(12):38-43.

72. Albino JE, Garcia R, Weintraub JA, Gansky SA. NIHfunded collaborating research centers to reduce oral health disparities: ECC. Presentation at the National Oral Health Conference, St. Louis, MO, April 2010.

73. Darby ML, Walsh M. Dental hygiene: theory and practice, 3rd ed. Philadelphia: Saunders Elsevier, 2010.

74. Inglehart MR, Tedesco L. Increasing orthodontic patient cooperation in the 21 st century: the role of cross-cultural communication issues. In: McNamara JA, Trotman CA, eds. Creating the compliant patient. Ann Arbor: Craniofacial Growth Series, Center for Human Growth and Development, University of Michigan, 1997:181-93.

75. Sullivan Commission on Diversity in the Health Care Workforce. Missing persons: minorities in the health professions, 2004. At: http://health-equity.pitt.edu/40/. Accessed: November 14, 2011.

76. Gurin P. The compelling need for diversity in education. Mich J Race \& Law 1999;5(1):363-425.

77. Tedesco L. The role of diversity in the training of health professionals. In: Smedley BD, Stith AY, Colburn L, Evans $\mathrm{CH}$, eds. The right thing to do, the smart thing to do: enhancing diversity in the health professions. Washington, DC: National Academy Press, 2001:36-56.

78. Tedesco LA. Post-affirmative action Supreme Court decision: new challenges for academic institutions. J Dent Educ 2005;69(12):1212-21.

79. Woolfolk MW, Price SS. Efforts to increase student diversity in allied, predoctoral, and advanced dental programs in the United States: a historical perspective. J Dent Educ 2012;76(1):51-64.

80. Drisko CL, Whittaker LP. Dental school faculty and the academic environment from 1936 to 2011: familiar features in a new context. J Dent Educ 2012;76(1):65-74.

81. Richards PS, Inglehart MR. An interdisciplinary approach to case-based teaching: does it create patient-centered and culturally sensitive providers? J Dent Educ 2006; 70(3):284-91.

82. Anderson JI, Patterson AN, Temple HJ, Inglehart MR. Lesbian, gay, bisexual, and transgender (LGBT) issues in dental school environments: dental student leaders' perceptions. J Dent Educ 2009;73(1):105-18.

83. Edelstein BL. Examining whether dental therapists constitute a disruptive innovation in US dentistry. Am J Public Health 2011;101(10):1831-5. 
84. Wetherhall S, Burrus B, Shugars D, Bader J. Cultural context in the effort to improve oral health among Alaska Native people: the dental health aide therapist model. Am J Public Health 2011;101(10):1836-40.

85. Batliner T, Brinton JT, Daniels DM, Wilson A, Gallegos J, Janis M, et al. 2011. An assessment of oral health on the Pine Ridge Indian Reservation. Battle Creek, MI: W.K. Kellogg Foundation, 2011.

86. Commission on Dental Accreditation. Accreditation standards for dental education programs. Chicago: American Dental Association, 2010. At: www.ada.org/sections/educationAndCareers/pdfs/predoc.pdf. Accessed: December $1,2011$.
87. Inglehart MR, Tedesco LA, Valachovic RW. Quality of life: refocusing dental education. In: Inglehart MR, Bagramian RA, eds. Oral health and quality of life. Chicago: Quintessence, 2002:183-92.

88. Formicola AJ, ed. New models of dental education: the Macy study report. J Dent Educ 2008;72(2 Suppl):3-136.

89. Bailit HL, Formicola AJ. About the Pipeline program. J Dent Educ 2010;74(10 Suppl):S5-S6.

90. Otto M. For want of a dentist. Washington Post, February $28,2007$. 